\title{
ANÁLISE SILVICULTURAL E ECONÔMICA DE PLANTIOS CLONAIS E SEMINAIS DE Tectona grandis L.f. EM SISTEMA TAUNGYA ${ }^{1}$
}

\begin{abstract}
Reginaldo Antonio Medeiros ${ }^{2}$, Haroldo Nogueira Paiva ${ }^{3}$, Helio Garcia Leite ${ }^{3}$, Silvio Nolasco Oliveira $\mathrm{Neto}^{3}$, Diogo Guido Streck Vendrúscolo ${ }^{4}$ e Fernando Thiago Silva ${ }^{4}$

RESUMO - O objetivo deste estudo foi realizar uma análise silvicultural e econômica de plantios clonais e seminais de Tectona grandis em monocultivo e em sistema taungya com Zea mays, no Município de Figueirópolis D'Oeste, MT. O experimento foi instalado em 2010 e compôs um fatorial $2 \times 2 \mathrm{em}$ blocos casualizados e quatro repetições. Avaliaram-se a altura total $(\mathrm{H})$, o diâmetro a $5 \mathrm{~cm}$ (DAB) e a 1,3 m (DAP) de altura em relação ao nível do solo, a área basal, o volume, a sobrevivência e a estimativa e tendência de crescimento da teca na idade atual e futura, além da produção de silagem do milho. Foram realizadas análises das receitas e custos totais de implantação e manutenção do sistema. Plantas clonais em monocultivo e no sistema Taungya apresentaram maior crescimento em altura total, DAB e DAP em relação às seminais. No monocultivo e no sistema Taungya, a produção $\left(\mathrm{m}^{3} \mathrm{ha}^{-1}\right)$ de plantas clonais em relação às seminais foi 33 e $30 \%$ superior, respectivamente. Os custos com insumos e atividades de implantação da teca foram superiores e os de manutenção, inferiores no sistema Taungya em relação ao monocultivo, tanto para plantios clonais quanto seminais. No sistema Taungya com plantas clonais, o milho reduziu em $21 \%$ os custos totais de implantação e manutenção em relação ao monocultivo; nas plantas seminais, a redução foi de $27 \%$. A teca no sistema Taungya cresce menos, porém apresenta tendência de recuperação após a retirada do milho, cuja presença amortiza custos de implantação e manutenção da teca em plantios clonais e seminais.
\end{abstract}

Palavras chave: Teca; Sistemas agroflorestais; Estimativa de crescimento.

\section{SILVICULTURAL AND ECONOMIC ANALYSIS OF CLONAL AND SEMINAL PLANTATIONS OF Tectona grandis L.F. IN TAUNGYA SYSTEM}

\begin{abstract}
The aim of this study was to perform a silvicultural and economic analysis of clonal and seminal plantations of Tectona grandis in monoculture and in Taungya system with Zea mays, in the municipality of Figueirópolis D'Oeste, MT. The experiment was established in 2010 and consisted of a $2 \times 2$ factorial in a randomized block design with four replications. We evaluated the following variables: total height $(H)$, diameter at $5 \mathrm{~cm}(D G H)$ and $1.3 \mathrm{~m}(\mathrm{DBH})$ above ground level, basal area, volume, survival, estimate and trend of growth of teak in the present and future ages and the production of maize silage. Analyses of total revenues and costs of implementation and maintenance of the system were performed. Clonal plants in monoculture and in Taungya system presented higher growth in total height, DGH and DBH in relation to seminal plants. In monoculture and in Taungya system, the production $\left(\mathrm{m}^{3} \mathrm{ha^{-1 }}\right)$ of clonal plants in relation to seminal plants was 33 and 30\% higher, respectively. The costs of inputs and planting activities of the teak were higher and the costs of maintenance were lower in Taungya system compared to monoculture, for both clonal and seminal plantations. In Taungya system with clonal plants, maize decreased by $21 \%$ the total establishment and maintenance
\end{abstract}

\footnotetext{
${ }^{1}$ Recebido em 27.06.2014 aceito para publicação em 12.08.2015.

${ }^{2}$ Instituto Federal de Mato Grosso, Campus Cáceres, Cáceres-MT; Universidade Federal de Viçosa, Programa de Pós-Graduação em Ciência Florestal, Viçosa-MG - Brasil. E-mail: <reginaldo_medeiros@ig.com.br>.

${ }^{3}$ Universidade Federal de Viçosa, Departamento de Engenharia Florestal, Viçosa, MG - Brasil. E-mail: <hnpaiva@ufv.br>, $<$ hgleite@gmail.com>e < snolasco@ufv.br>.

${ }^{4}$ Instituto Federal de Mato Grosso, Campus Cáceres, Graduando em Engenharia Florestal, Cáceres-MT, Brasil. E-mail: $<$ diogoguido@hotmail.com>e $<$ fernando_thiago06@hotmail.com>.
} 
costs compared to monoculture, and for seminal plants the reduction was 27\%. Teak grows less in Taungya system, but shows signs of recovery after the removal of maize. The presence of maize amortizes costs of implementation and maintenance of teak in seminal and clonal plantations.

Keywords: Teak; Agroforestry systems; Growth estimate.

\section{INTRODUÇ̃̃̃O}

A área de florestas plantadas no mundo, em 2010, totalizavam 264 milhões de hectares, o que representa $7 \%$ da cobertura florestal do planeta. Desse total, mais de 20 milhões de hectares são cultivados com as principais espécies de eucaliptos (IGLESIAS-TRABADO et al., 2011). No entanto, a teca (Tectona grandis L.f.) ocupava uma área de 3,59 milhões de ha $(1,36 \%$ ) (FAO, 2010). No Brasil, a área de florestas plantadas em 2012 era de 6.732 .141 ha, sendo $70,8 \%$ ocupadas com eucalipto, $22 \%$ com pinus e $7,2 \%$ com outras espécies, entre as quais a teca, com 1\% (67.329 ha) (ABRAF, 2013).

Nativa da Índia, Myanmar, Tailândia e Laos, atualmente $80 \%$ da área cultivada de teca está na Ásia, 13\% na África e 7\% na América Latina, onde foi introduzida em Trinidade e Tobago em 1913. No Brasil, seu cultivo em escala comercial iniciou-se em 1968, em Cáceres, Mato Grosso. Atualmente, o Estado possui mais de 60.000 ha de área plantada, o que corresponde à maior área da América Latina (Panamá: 55.000 ha, Equador: 45.000 ha e Costa Rica: 35.000 ha) (AREFLORESTA, 2012; CAMINO; AYMERICH, 2013).

Sua madeira é considerada de alta qualidade, podendo ser utilizada em móveis de luxo, construção naval, elementos estruturais, pisos laminados, entre outros. É leve, durável, com boa estabilidade dimensional, não se corrói em contato com metal, apresenta boa trabalhabilidade e dureza, resistência a cupim, produtos químicos, fungos e umidade (KEOGH, 2013).

Segundo Ângelo et al. (2009), o valor de uma floresta de teca aos 25 anos de idade pode variar de US\$4,973.09 a US\$14,059.45 por hectare - sua maturidade financeira ocorre dos 14 aos 20 anos. Conforme dados da FAMATO (2013), ao final de 20 anos o custo total de produção é de $\mathrm{R} \$ 103.126,90 \mathrm{ha}^{-1}$ e gera uma receita total de $\mathrm{R} \$ 295.221,00 \mathrm{ha}^{-1}$, considerando-se um preço médio de $\mathrm{R} \$ 1.000,00 \mathrm{~m}^{-3}$.

Atualmente, mais do que aumentar a área plantada, há preocupação em melhorar a produtividade das plantações, principalmente pela seleção de genótipos mais produtivos e, também, pela adoção de sistemas de produção mais sustentáveis.

A seleção de genótipos superiores, adaptados às condições edafoclimáticas, pode melhorar a produtividade, produzir matéria-prima de melhor qualidade e, até mesmo, reduzir a idade de corte (GONÇALVES et al., 2005; TONINI et al., 2006). No entanto, Costa et al. (2007) e Schuuhli e Paludzszyn Filho (2010) comentaram sobre a necessidade de definir estratégias e programas de melhoramento e seleção de genótipos da espécie para melhorar os índices de produtividade das plantações de teca.

Quanto ao desenvolvimento de sistemas de produção mais sustentáveis, destaca-se o sistema Taungya, um modelo de sistema agroflorestal que envolve o plantio consorciado com espécies arbóreas e agrícolas e pode ser alternativa para o cultivo de teca. O sistema objetiva diminuir os custos de implantação e manutenção nos primeiros anos das plantações florestais, graças ao aproveitamento das atividades de manutenção da cultura agrícola e às receitas oriundas da comercialização deseus produtos(SCHLÖNVOIGT; BEER, 2001). Originou-se no século XIX, em Myanmar, buscando maior eficiência nos plantios de Tectona grandis (BLANDFORD, 1958). No Brasil, seu uso é relatado a partir de 1962, em consórcio com Eucalyptus alba e milho (GURGEL FILHO, 1962). No entanto, apesar da importância da cultura no Mato Grosso, informações científicas sobre a silvicultura da espécie envolvendo material genético utilizado, consórcio com culturas agrícolas e monitoramento do crescimento e produção são incipientes, escassas ou, muitas vezes, de forma empírica.

Este estudo teve como objetivo realizar uma análise silvicultural e econômica de plantios clonais e seminais de Tectona grandis em monocultivo e em sistema Taungya com Zea mays, no Município de Figueirópolis D’Oeste, MT.

\section{MATERIALE MÉTODOS}

O experimento foi instalado em janeiro de 2010 , no Município de Figueirópolis D’Oeste, Sudoeste do 
Estado de Mato Grosso. A área experimental situa-se nas coordenadas geográficas de latitude Sul $15^{\circ} 24^{\prime} 27^{\prime \prime}$, longitude Oeste $58^{\circ} 45^{\prime} 56^{\prime \prime}$ e altitude de $370 \mathrm{~m}$.

O clima da região é tropical Aw, segundo a classificação de Koppen, caracterizado por duas estações ao longo do ano, sendo uma chuvosa de outubro a abril e outra seca de maio a setembro. A temperatura média anual varia de 25 a $38^{\circ} \mathrm{C}$ e as precipitações pluviométricas, em torno de $1.500 \mathrm{~mm}^{2} \mathrm{ano}^{-1}$. A vegetação original da região é composta de Floresta Estacional e Savana Gramíneo-Lenhosa. O local onde o experimento foi implantado era ocupado com pastagem (Brachiaria brizantha (A. Rich.) Stapf vr. Marandu).

O relevo é plano a suavemente ondulado, com predomínio de solos do tipo Cambissolo Háplico Tb Eutrófico léptico. Coletaram-se amostras de solo, na profundidade de 0 a $20 \mathrm{~cm}$, nas parcelas experimentais, para análises física e química, as quais apresentaram pH 6,36 em água; 5,29 e 96,79 $\mathrm{mg} \mathrm{dm}^{-3}$ de $\mathrm{P}$ e K; e 5,56; 0,72; 0,0; e 1,91 $\mathrm{cmol}_{\mathrm{c}} \mathrm{dm}^{-3}$ de Ca, $\mathrm{Mg}$, Al e H. Os micronutrientes $\mathrm{Zn}, \mathrm{Cu}, \mathrm{Fe}, \mathrm{Mn}$ e $\mathrm{B}$ e enxofre exibiram teores de 5,$86 ; 2,72 ; 114,02 ; 120,59 ; 0,43$; e $3,37 \mathrm{mg}$ $\mathrm{kg}^{-1}$, respectivamente. $\mathrm{O}$ teor de matéria orgânica foi de $16,23 \mathrm{~g} \mathrm{dm}^{-3}$. A fração areia apresentou teor de 51,4 dag $\mathrm{kg}^{-1}$, silte $16,5 \mathrm{dag}_{\mathrm{kg}^{-1}}$ e argila $32,1 \mathrm{dag} \mathrm{kg}^{-1}$.

O delineamento experimental foi em blocos casualizados com quatro repetições. Foram avaliados quatro tratamentos (fatorial $2 \times 2$ ), sendo dois tipos de mudas de teca (clonal e seminal), na presença e ausência de milho, que é tradicionalmente cultivado na região para produção de silagem. As parcelas constaram de sete linhas de plantio de teca no sentido leste-oeste, com seis plantas por linha, no espaçamento 4 × $2 \mathrm{~m}$ (42 plantas que, descontada a bordadura, totalizaram 20 plantas úteis) e área de $364 \mathrm{~m}^{2}(13 \times 28 \mathrm{~m})$.

Para o preparo do solo foram realizadas três gradagens, sendo duas com grade aradora e uma com grade niveladora, na profundidade média de $30 \mathrm{~cm}$. As covas foram abertas manualmente, com dimensões de $20 \mathrm{~cm}$ de diâmetro e $30 \mathrm{~cm}$ de profundidade.

As mudas clonais de teca foram fornecidas por uma empresa reflorestadora e as seminais, adquiridas de produtores de mudas da região. Apresentavam altura média de $20 \mathrm{~cm}$ aos três meses de idade. As clonais foram produzidas em tubetes de $55 \mathrm{~cm}^{3}$ e as seminais, em sacolas plásticas de $144 \mathrm{~cm}^{3}$ de capacidade $(9 \times 16 \mathrm{~cm})$.
O plantio foi realizado manualmente, e não houve a aplicação de corretivo ou fertilizante, devido ao fato de a fertilidade do solo atender à demanda da cultura florestal. O replantio foi realizado 30 dias após o plantio.

O controle de formigas e cupins foi realizado antes da implantação e durante a condução do experimento.

O manejo da matocompetição foi realizado com capina manual e roçada mecanizada. Nas parcelas em monocultivo, foi aplicado herbicida aos 60 dias após o plantio da teca.

Em 2010, o plantio do milho (cultivar AG 8088 YG) foi realizado 30 dias após o da teca e em 2011 (cultivar BM3061), no início do mês de fevereiro. Plantaram-se três fileiras de milho, espaçadas $0,8 \mathrm{~m}$ e distantes 1,2 $\mathrm{m}$ da linha de plantio da teca, perfazendo um estande de 52.500 plantas por hectare. Foram aplicados 120 $\mathrm{kg} \mathrm{ha}^{-1}$ de sulfato de amônio nas entrelinhas da cultura agrícola, com o auxílio de adubadeira manual.

A colheita do milho foi realizada manualmente. Em seguida, usou-se a ensiladeira acoplada a um trator agrícola, para trituração e produção de silagem. Coletaram-se amostras de silagem, com volume e peso conhecidos, para obtenção da densidade. Para o cálculo da quantidade de silagem (toneladas), multiplicou-se o volume de silagem na parcela pela sua densidade.

A partir de seis meses do plantio da teca, mensurou-se semestralmente seu crescimento em altura total $(\mathrm{H})$ com régua graduada até 24 meses e mediu-se o diâmetro basal a $5 \mathrm{~cm}$ de altura em relação ao nível do solo (DAB), com paquímetro digital. Após os 24 meses de idade, mediu-se o diâmetro a $1,3 \mathrm{~m}$ de altura em relação ao nível solo (DAP) com fita diamétrica, calculando a área basal e o volume. Também, avaliou-se a sobrevivência aos 36 meses de idade.

Nas idades de 30 e 36 meses, o DAB foi obtido pelas equações 1 e 2 , uma vez que essa variável não foi mensurada nessas idades.

$$
\begin{aligned}
& D A B C=2,77966+1,14233 D A P c\left(\mathrm{R}_{\mathrm{adj}}^{2}=84,6\right) \\
& D A B S=1,82594+1,31609 D A P s\left(\mathrm{R}_{\mathrm{adj}}^{2}=82,2\right)
\end{aligned}
$$

em que:

$D A B c$ : diâmetro a $5 \mathrm{~cm}$ de altura em relação ao nível do solo de plantas clonais;

$D A B s$ : diâmetro a $5 \mathrm{~cm}$ de altura em relação ao nível do solo de plantas seminais;

Revista Árvore, Viçosa-MG, v.39, n.5, p.893-903, 2015 
$D A P c$ : diâmetro a 1,3 $\mathrm{m}$ de altura em relação ao nível do solo de plantas clonais; e

$D A P s$ : diâmetro a 1,3 $\mathrm{m}$ de altura em relação ao nível do solo de plantas seminais.

Para estimativa e tendência de crescimento em altura e diâmetro basal de teca em idades futuras (até 48 meses), utilizou-se o Modelo de Gompertz (equação 3), através do software CurvExpert.

$$
\mathrm{y}=\mathrm{ae}^{-\mathrm{e}(\mathrm{b}-\mathrm{cx})}+\varepsilon
$$

em que $\mathrm{y}=$ variável analisada; $\mathrm{a}=\mathrm{assíntota} ; \mathrm{b}=$ ponto de inflexão; $\mathrm{c}=$ taxa de crescimento $\mathrm{e}=$ idade.

Para análise das equações ajustadas do Modelo de Gompertz, utilizaram-se coeficiente de correlação, erro-padrão, análise gráfica do resíduo e teste L\&O, conforme Leite e Oliveira (2002). Também, foi utilizado o teste de Identidade de Modelo para verificar a igualdade de parâmetros das equações estimadas para cada tratamento, conforme Regazzi e Silva (2010).

O volume individual por árvore com casca foi estimado utilizando-se a equação ajustada por Cruz et al. (2008), através do modelo de Schumacher e Hall, na forma linear, para povoamentos jovens de teca (eq. 4).

$\operatorname{Ln}(V C C)=-8,57046+1,07588 \operatorname{Ln}(D A P)+$

$+1,27429 \operatorname{Ln}(\mathrm{H}) \mathrm{R}^{2}=0,987$

em que $V c c=$ volume total com casca, em $\mathrm{m}^{3} ; D A P$ $=$ diâmetro a $1,30 \mathrm{~m}$ de altura em relação ao nível do solo, em cm; $H=$ altura total, em m; e $L n=$ logaritmo neperiano.

As informações anuais dos custos, receitas e rendimentos operacionais foram apresentadas em fluxo de caixa anual para cada tratamento, com base nos mercados local e regional.

As atividades e os custos foram agrupados nas categorias de insumos (formicida, cupinicida, herbicida, semente de milho, fertilizante, mudas de teca clonal e seminal), atividades de implantação (aplicação de herbicida, gradagem, nivelamento, coveamento, plantio da teca, replantio, plantio do milho e aplicação de fertilizante) e atividades de manutenção e colheita (capina, coroamento da teca, roçada nas linhas, roçada nas entrelinhas, desbrota, desrama, aplicação de herbicida pós-plantio, controle de formigas e cupins, capina do milho, colheita do milho e ensilagem).

Revista Árvore, Viçosa-MG, v.39, n.5, p.893-903, 2015
Para análise da viabilidade econômica do sistema, foram realizadas análises dos custos totais dos insumos e das atividades de implantação e manutenção e das receitas totais de cada tratamento. Também, foi avaliada a amortização dos custos de implantação e manutenção do sistema pela cultura agrícola.

\section{RESULTADOS}

\subsection{Crescimento}

As variáveis de crescimento apresentaram variâncias homogêneas pelo teste de Cochran ( $p>0,05)$, e as médias tiveram distribuição normal pelo teste de Liliefors $(p>0,05)$.

A interação tipo de muda e presença/ausência do milho não surtiu efeito significativo ( $p>0,05)$, ao passo que os fatores, isoladamente, apresentaram efeito significativo sobre as variáveis estudadas (Tabela 1).

Aos 36 meses após o plantio, verificou-se que há diferença significativa entre o tipo de muda e a presença e ausência da cultura agrícola em todas as variáveis em estudo. Plantas clonais tiveram crescimento em altura, DAB, DAP, área basal e volume superior às seminais. De forma semelhante, aquelas em monocultivo apresentaram superioridade em relação às do sistema Taungya (Figura 1).

Plantas clonais e seminais em monocultivo tiveram superioridade de $9 \%$ e $6 \%$ em altura, $10 \%$ e $6 \%$ em DAB, $18 \%$ e $7 \%$ em DAP, $24 \%$ e $20 \%$ em área basal e $23 \%$ e $20 \%$ em volume, respectivamente, se comparadas àquelas no sistema Taungya.

Ao comparar plantas clonais e seminais no monocultivo, observou-se superioridade de $11 \% \mathrm{em}$ altura, $12 \%$ em DAB, $18 \%$ em DAP, 34\% em área basal e $32 \%$ em volume. No sistema Taungya, a superioridade foi de $8 \%$ em altura e DAB, $13 \%$ em DAP, $31 \%$ em área basal e $30 \%$ em volume.

Aos 36 meses, plantas clonais em monocultivo e no sistema Taungya apresentaram 99\% de sobrevivência, enquanto plantas seminais em monocultivo, $95 \%$ e, no sistema Taungya, $89 \%$ de sobrevivência.

\subsection{Estimativa e tendência de crescimento}

Para estimativa e tendência de crescimento em altura total e diâmetro basal nas idades de 42 e 48 meses, 
Tabela 1 - Resumo da análise de variância (Quadrado Médio) da altura (H), diâmetro a $5 \mathrm{~cm}$ (DAB) e a 1,3 m de altura em relação ao nível do solo (DAP), área basal $(\mathrm{G})$ e volume (V) de teca clonal e seminal, em sistema Taungya e monocultivo, aos 36 meses de idade.

Table 1 - Summary of the analysis of variance (Mean Square) of the height (H), diameter at $5 \mathrm{~cm}(D G H)$ and $1.3 \mathrm{~m}$ above ground level $(D B H)$, basal area $(G)$ and volume $(V)$ of clonal and seminal teak in Taungya and monoculture systems, at 36 months old.

\begin{tabular}{lcccccccccccc}
\hline \multirow{2}{*}{ Fonte de Variação o } & \multicolumn{1}{c}{$H$} & \multicolumn{3}{c}{$H$} & \multicolumn{2}{c}{$D A B$} & \multicolumn{2}{c}{$D A P$} & \multicolumn{2}{c}{$G$} & \multicolumn{2}{c}{$V$} \\
\cline { 2 - 13 } & & $Q M$ & $p$ & $Q M$ & $p$ & $Q M$ & $p$ & $Q M$ & $p$ & $Q M$ & $p$ \\
\hline Bloco & 3 & 0,040 & 0,817 & 0,043 & 0,915 & 0,026 & 0,929 & 0,205 & 0,804 & 6,718 & 0,766 \\
Tipo de muda & 1 & 2,588 & 0,002 & 5,860 & 0,001 & 6,329 & 0,000 & 17,492 & 0,000 & 409,470 & 0,001 \\
Presença do milho & 1 & 1,441 & 0,009 & 3,806 & 0,004 & 2,637 & 0,004 & 6,797 & 0,009 & 175,620 & 0,011 \\
Interação & 1 & 0,087 & 0,432 & 0,248 & 0,350 & 0,270 & 0,247 & 0,642 & 0,336 & 13,138 & 0,408 \\
Erro & 9 & 0,129 & & 0,255 & & 0,176 & & 0,621 & & 17,439 & \\
CV & & $7,7 \%$ & & $8 \%$ & & $11,5 \%$ & & $27 \%$ & & $26,2 \%$ & \\
\hline
\end{tabular}

Onde; $p=$ valor $\mathrm{p} ; \mathrm{gl}=$ graus de liberdade, $\mathrm{CV}=$ coeficiente de variação.

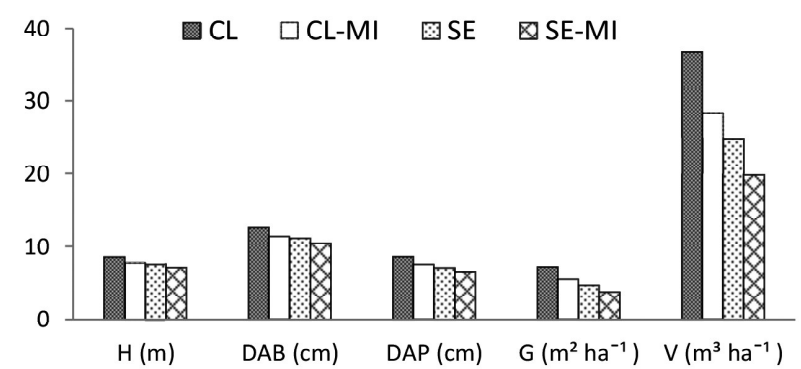

Figura 1 - Altura total $(\mathrm{H})$, diâmetro a $5 \mathrm{~cm}$ em relação ao nível do solo (DAB) e a 1,3 m de altura em relação ao nível do solo (DAP); área basal (G) e volume (V) de teca clonal e seminal, em sistema Taungya e monocultivo, aos 36 meses de idade. $\mathrm{CL}=$ clonal; $\mathrm{SE}=$ seminal; e $\mathrm{MI}=$ milho.

Figure 1 - Total height $(H)$, diameter at $5 \mathrm{~cm}$ above ground level (DGH) and $1.3 \mathrm{~m}$ above ground level (DBH); basal area $(G)$ and volume (V) of clonal and seminal teak in Taungya and monoculture systems, at 36 months, being: $C L=$ clonal; $S E=$ seminal; and $M I=$ maize.

as equações do modelo de Gompertz apresentaram bom ajuste, com alto coeficiente de correlação entre as variáveis dependentes (H e DAB) e independentes (idade) e baixo erro-padrão. Os valores observados e estimados foram iguais pelo teste L\&O nas variáveis em plantas clonais, em monocultivo e consorciadas e em altura total de plantas seminais, sendo diferentes no caso da variável DAB de plantas seminais.

Conforme o teste de identidade de modelo, as equações ajustadas para predição de crescimento em altura total e diâmetro basal diferiram entre si, em todos os tratamentos analisados.
Com as equações ajustadas, estimou-se o crescimento em altura total e diâmetro basal até a idade de 48 meses (Figura 2).

O crescimento em altura de plantas clonais foi superior às seminais, considerando o mesmo sistema de cultivo. Plantas seminais em monocultivo apresentaram crescimento superior em relação às clonais no sistema Taungya apenas no período de consorciamento. Entretanto, com a projeção do crescimento em altura em idades futuras, verificou-se que, após esse período, houve tendência de recuperação do crescimento das plantas clonais e seminais que estavam consorciadas, inclusive superando aquelas em monocultivo, o que demonstra o efeito da competição.

Comportamento semelhante foi verificado para diâmetro basal. Entretanto, nas idades futuras a tendência de crescimento de plantas clonais em monocultivo se manteve superior em relação ao sistema Taungya. Em plantas seminais, esse efeito foi menos acentuado.

\subsection{Análise de custos e receitas}

Considerando os custos totais de cada tratamento, observou-se que insumos representaram $13 \%$ e $12 \%$ em plantios clonais no sistema Taungya e no monocultivo, respectivamente; em plantios seminais, representaram $15 \%$, independentemente do sistema de cultivo. Entre os tratamentos, os maiores custos com insumos foram nesta ordem: plantios seminais no sistema Taungya, clonais no mesmo sistema de cultivo, seminais em monocultivo e clonais também no mesmo sistema de cultivo (Figura 3).

Revista Árvore, Viçosa-MG, v.39, n.5, p.893-903, 2015 

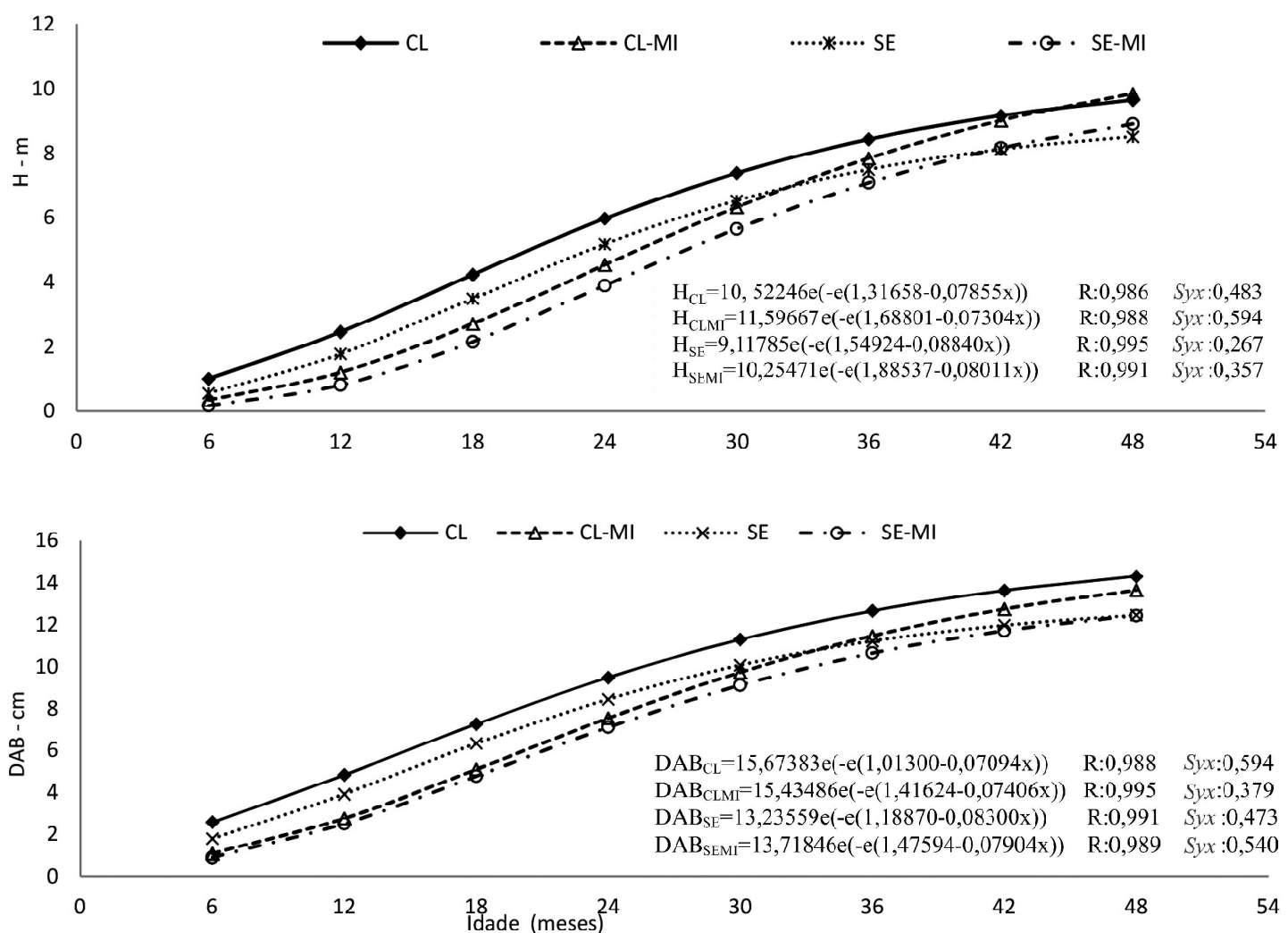

Figura 2 - Estimativa e tendência de crescimento em altura total (H) e diâmetro basal (DAB) de teca clonal e seminal, em sistema Taungya e monocultivo. $\mathrm{CL}=$ clonal, $\mathrm{SE}=$ seminal, $\mathrm{MI}=$ milho, $\mathrm{x}=$ idade, $\mathrm{R}=$ coeficiente de correlação e Syx: erro-padrão da estimativa.

Figure 2 - Estimate and trend of growth in total height $(H)$ and basal diameter (DGH) of clonal and seminal teak in Taungya and monoculture systems, being: $C L=$ clonal, $S E=$ seminal, $M I=$ maize, $x=$ age, $R=$ correlation coefficient, and Syx = standard error of the estimate.

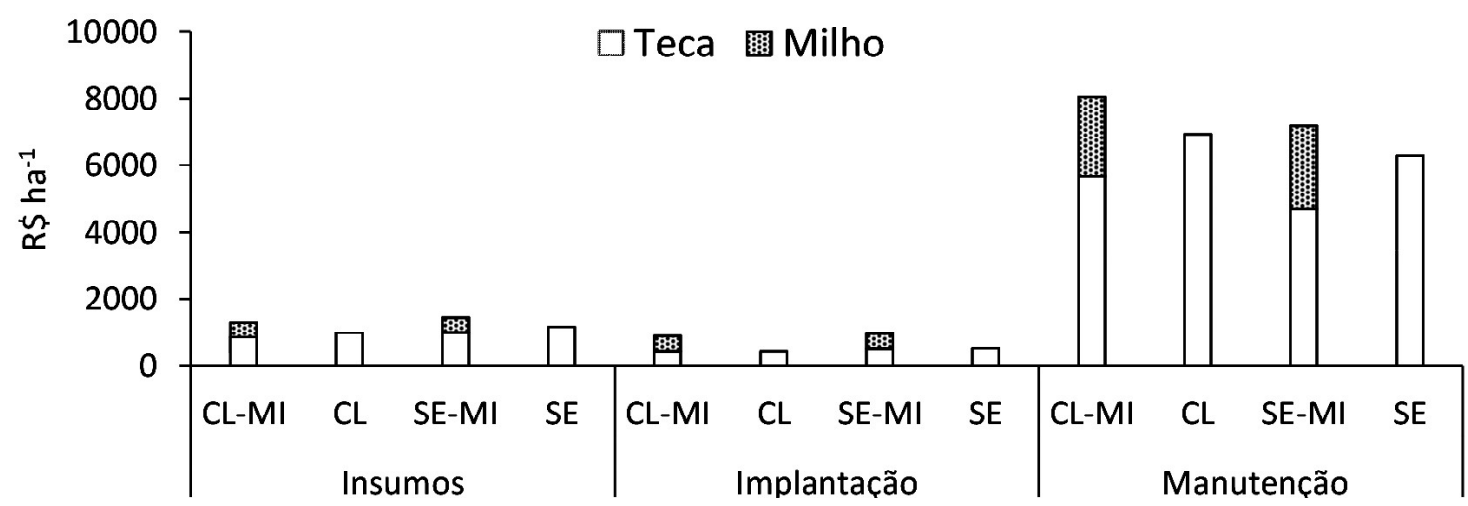

Figura 3 - Custos de insumos, atividades de implantação e manutenção de plantios de teca clonal e seminal, em sistema Taungya e monocultivo, no período de 36 meses de idade, em que: $\mathrm{CL}=$ clonal, $\mathrm{SE}=$ seminal e $\mathrm{MI}=$ milho.

Figure 3 - Costs of inputs, implementation and maintenance activities of clonal and seminal plantations of teak in Taungya and monoculture systems, in the period of 36 months, where: $C L=$ clonal, $S E=$ seminal and $M I=m a i z e$.

Revista Árvore, Viçosa-MG, v.39, n.5, p.893-903, 2015 
Dos custos totais, os custos com as atividades de implantação representaram 9\% e 5\% em plantios clonais e $10 \%$ e $7 \%$ em plantios seminais, no sistema Taungya e no monocultivo, respectivamente. Os maiores custos com atividades de implantação foram em plantios seminais no sistema Taungya, clonais no mesmo sistema de cultivo e seminais e clonais no monocultivo.

Os custos com atividades de manutenção representaram $78 \%$ e $83 \%$ dos custos totais em plantios clonais e $75 \%$ e $79 \%$ em plantios seminais no sistema Taungya e no monocultivo, respectivamente. Plantios clonais e seminais no sistema Taungya e clonais e seminais em monocultivo apresentaram, nessa ordem, os maiores custos com atividades de manutenção.

Para o componente agrícola, os custos representaram, em média, $13 \%, 14 \%$ e $73 \%$ com insumos, implantação e manutenção, respectivamente.

A produção de silagem foi de 14 e 19 toneladas por hectare no primeiro e no segundo ano, respectivamente. Nesse período, seu custo médio de produção foi de $\mathrm{R} \$ 101,00 \mathrm{t}^{-1}$.

No sistema Taungya, houve reduções de $21 \%$ e $27 \%$ nos custos das atividades de implantação e manutenção para plantios clonais e seminais em relação ao monocultivo, respectivamente (Figura 4).

\section{DISCUSSÃO}

\subsection{Crescimento}

Plantas clonais apresentaram maior crescimento e produção em relação às seminais, independentemente

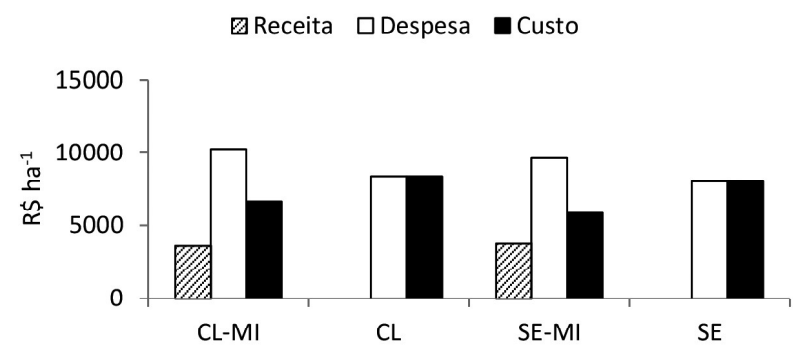

Figura 4 - Receita e custos de um sistema Taungya e monocultivo com teca clonal e seminal e milho, no período de 36 meses de idade. $\mathrm{CL}=$ clonal, $\mathrm{SE}=$ seminal $\mathrm{e} \mathrm{MI}=$ milho.

Figure 4-Revenue and costs of Taungya and monoculture systems, with clonal and seminal teak and maize, in the period of 36 months, being: $C L=$ clonal, $S E=$ seminal, $M I=$ maize. do sistema de cultivo. Esses resultados corroboram com informações de empresas reflorestadoras no Estado de Mato Grosso, em que mudas de teca oriundas de clones selecionados apresentam ganhos de produtividade nas idades iniciais de até 36\%. Smit et al. (2011) verificaram produtividade 39\% superior de plantios clonais em relação aos seminais, aos 5,2 anos de idade, ambos cultivados em monocultivo, no Município de Tangará da Serra, MT, que apresenta características edafoclimáticas semelhantes às deste estudo. Tonini et al. (2006) constataram, por meio de curvas de índice de sítio, diferenças no padrão do crescimento em altura dominante entre povoamentos de Eucalyptus saligna originados de mudas por sementes e clones, inclusive para tipos de solo.

Para Gonçalves et al. (2005), a escolha de genótipos melhorados tem sido responsável pelos maiores incrementos de produtividade na silvicultura brasileira. Schuuhli e Paludzszyn Filho (2010) comentaram que a seleção cuidadosa de genótipos superiores poderá aumentar substancialmente a produtividade da teca.

Atualmente, esses ganhos de produtividade e a demanda de madeira em qualidade e quantidade exigidas pelo mercado têm elevado o interesse por clones de teca mais produtivos. No entanto, Costa et al. (2007) e Schuuhli e Paludzszyn Filho (2010) alertaram para a necessidade de definir estratégias em curto prazo associado a programas de melhoramento em longo prazo, visando ao fornecimento de material genético para atender à demanda crescente de mudas da espécie. Nesse caso, a clonagem seria a maneira mais eficiente de propagar esses genótipos superiores para a produção de mudas (TONINI et al., 2006).

Aos 36 meses de idade, plantas em monocultivo apresentaram maior crescimento e produção, em comparação com aquelas no sistema Taungya, independentemente do tipo de muda. Gurgel Filho (1962), Couto et al. (1994), Daniel et al. (2004), Macedo et al. (2010) e Moretti et al. (2014) comentaram que o milho apresenta crescimento rápido, atingindo um porte que pode trazer prejuízo ao crescimento das espécies florestais em sistema Taungya, principalmente em virtude da competição por luz na fase inicial do plantio florestal, que depende da densidade e proximidade das plantas consorciadas.

Revista Árvore, Viçosa-MG, v.39, n.5, p.893-903, 2015 


\subsection{Estimativa e tendência de crescimento}

Até os 36 meses de idade, observou-se que o crescimento em altura e diâmetro basal de plantas clonais foi superior às seminais, e plantas em monocultivo cresceram mais que aquelas no sistema Taungya. Entretanto, ao analisar as curvas de crescimento dessas variáveis, obtidas por meio da modelagem dos dados, verificou-se tendência de recuperação do crescimento das plantas consorciadas com milho 30 meses após o fim do consórcio.

Essa recuperação do crescimento é atribuída à ausência do milho, que competia por fatores de crescimento com a teca(GURGEL FILHO, 1962; COUTO et al., 1994; DANIEL et al., 2004; MACEDO et al., 2010; MORETTI et al., 2014). Entretanto, a teca no sistema Taungya pode ter-se beneficiado com as práticas de manejo do milho, como adubações (ALVARADO, 2006; SALDANHA et al., 2014; MORETTI etal., 2014) e capinas, que implicam revolvimento e incorporação de resíduos, acelerando a mineralização de nutrientes (GONÇALVES et al., 2005).

Diante do exposto, fica evidente a importância de compreender a dinâmica e os processos de crescimento e produção dos componentes do sistema Taungya, sobretudo o componente florestal. Cruz et al. (2008) e Campos e Leite (2013) afirmaram que a modelagem do crescimento e da produção é imprescindível para o gerenciamento e manejo das plantações florestais, principalmente para teca, uma vez que decisões sobre seu manejo têm sido tomadas de forma empírica (LEITE et al., 2006).

Neste estudo, o modelo de Gompertz utilizado para ajuste das equações para predição e prognose do crescimento em altura e diâmetro basal em função da idade apresentou parâmetros significativos, estatisticamente aceitos e com realismo biológico. Campos e Leite (2013) comentaram que modelos que apresentam relação funcional $Y=f(i)$ devem ser utilizados em compartimentos homogêneos, com tendência de crescimento bem definida, como nesta pesquisa.

\subsection{Análise de custos e receitas}

Observou-se que os custos com insumos foram superiores nos plantios seminais em relação aos clonais, devido ao maior número de mudas para replantio e custos dessa atividade.

Revista Árvore, Viçosa-MG, v.39, n.5, p.893-903, 2015
No sistema Taungya, os custos de implantação e manutenção foram $19 \%$ superiores ao do monocultivo de plantios clonais e $17 \%$ de plantios seminais. Passos (1990) comentou que os sistemas consorciados demandam maior investimento, aumentando os custos de implantação do sistema. Dubé et al. (2002), ao analisarem aspectos econômicos de um sistema agroflorestal com eucalipto, culturas agrícolas e forrageiras, na região do Cerrado do Brasil, verificaram que os custos de implantação e manutenção de 1 ha de eucalipto representam mais de um terço do gasto total de criação de bovinos, manutenção e colheita dos componentes do sistema agroflorestal em estudo. Entretanto, com a receita advinda da silagem de milho e o aproveitamento das atividades de manutenção da cultura agrícola, houve redução de $21 \%$ do custo de implantação e manutenção do sistema Taungya em plantios clonais e $27 \%$ nos seminais, no período de 36 meses. Os resultados corroboram relatos de Passos (1990), Schlönvoigt e Beer (2001), Dubé et al. (2002) e Macedo et al. (2010) de que cultivos agrícolas diminuem os custos de implantação, principalmente durante os primeiros anos.

Passos et al. (1992) verificaram que o consórcio de Eucalyptus grandis e milho aos 25 meses reduziu em $20 \%$ os custos de implantação da cultura florestal. Moretti (2013), ao realizar análise econômica de um sistema Taungya com teca e milho em área experimental no Município de Figueirópolis D’Oeste, MT, verificou redução média de $22,55 \%$ dos custos totais de instalação e condução dos tratamentos, aos 14 meses. Para Couto et al. (1994), as reduções de custos de implantação florestal observadas em sistemas agroflorestais podem atingir até $60 \%$.

A produção de silagem foi $45 \%$ menor se comparada com a média regional. Isso se deve à redução de estande de plantas de milho no sistema Taungya e ao déficit hídrico ocorrido no período experimental.

Conforme informações de produtores rurais do município onde se localiza a área experimental, em monocultivo, a produtividade média de silagem é de $30 \mathrm{t} \mathrm{ha}^{-1}$ a cada cultivo, considerando um estande de 75.000 plantas por hectare. Couto et al. (1998) e Macedo et al. (2006) comentaram que a produtividade do milho consorciado com eucalipto nos espaçamentos tradicionais, em sistema Taungya, pode ser afetada pela redução do estande de plantas de milho devido à presença da cultura florestal. Macedo et al. (2006) verificaram que a produção 
de milho, em consórcio com eucalipto implantado no espaçamento de 10 × 4 m, aos 28 meses, em Paracatu, $\mathrm{MG}$, foi menor se comparada ao monocultivo devido à competição, principalmente por luz, e ao déficit hídrico ocorrido no período experimental.

\section{CONCLUSÃO}

Plantas clonais apresentam altura total, diâmetro a $5 \mathrm{~cm}$ e a $1,3 \mathrm{~m}$ de altura em relação ao nível do solo, área basal e volume superiores às seminais, aos 36 meses de idade, no sistema Taungya e no monocultivo.

Plantas de teca no sistema Taungya crescem menos, porém apresentam tendência de recuperação após a retirada do componente agrícola.

A presença do componente agrícola amortiza custos de implantação e manutenção da teca em plantios clonais e seminais.

\section{AGRADECIMENTOS}

À FAPEMAT, ao IFMT, à Floresteca, à EMPAER, à Prefeitura de Figueirópolis D'Oeste-MT, à Coopnoroeste Lacbom, ao Sicredi Noroeste, ao Sr. Antônio Medeiros e família e aos demais colaboradores, pelo apoio; ao Professor Dr. Carlos A. M. Passos (in memoriam), dedicamos este trabalho.

\section{REFERÊNCIAS}

ABRAF. Anuário estatístico da ABRAF 2013, ano base 2012. Brasília: 2013. 148p.

AREFLORESTA. Mato Grosso tem maior área plantada de Teca da América Latina. Disponível em: http://www.arefloresta.org.br/noticias/ noticia.asp?id=34. Acesso em: 20 ago. 2014 .

\section{ALVARADO, A. Nutricion y fertilizacion} de la Teca. Quito: INPOFOS, 2006. (Informaciones Agronomicas, 61).

ÂNGELO, H.; SILVA, V.S.M.; SOUZA, A.N.; GATTO, A.C. Aspectos financeiros da produção de Teca no estado de mato grosso.

FLORESTA, v.39, n.1, p.23-32, 2009.

BLANDFORD, H.R. Highlights of one hundred years of forestry in Burma. Empire Forestry Review, v.37, n.1, p.33-42, 1958.
CAMINO, R.; AYMERICH, J.P.M. La teca en América Latina. In: CAMINO, R. Las plantaciones de teca en América Latina: mytos y realidades. Turrialba: CATIE, 2013. p.30-41. (Série Técnica/Informe Técnico/ CATIE, 397)

CAMPOS, J.C.C.; LEITE, H.G. Mensuração florestal: perguntas e respostas. 4.ed. Viçosa, MG: Universidade Federal deViçosa, 2013. 605p.

COUTO, L.; DANIEL, O.; GARCIA, R.; BOWERS, W.; DUBÉ, F. Sistemas agroflorestais com eucaliptos no Brasil: uma visão geral. Viçosa, MG: SIF, 1998. 49p. (Documento SIF, 17).

COUTO, L.; BINKLEY, D.; BETTERS, D.R.; MONIZ, C.V.D. Intercropping eucalypts with maize in Minas Gerais, Brazil. Agroforestry Systems, v.26, n.1, p.147-156, 1994.

COSTA, R.B.; RESENDE, M.D.V.; SILVA, V.S.M. Experimentação e seleção no melhoramento genético de TECA (Tectona grandis L.f.

Floresta e Ambiente, v.14, n.1, p.76-92, 2007.

CRUZ, J.P.; LEITE, H.G.; SOARES, C.P.B.; CAMPOS, J.C.C.; SMIT, L.; NOGUEIRA, G.S.; OLIVEIRA, M.L.R. Modelos de crescimento e produção para plantios comerciais jovens de Tectona grandis em Tangará da Serra, Mato Grosso. Revista Árvore, v.32, n.5, p.821-828, 2008.

DANIEL, O.; BITTENCOURT, D.; GELAIN, E. Avaliação de um sistema agroflorestal eucaliptomilho no Mato Grosso do Sul.

Agrossilvicultura, v. 1, n.1, p.15-28, 2004

DUBE, F.; COUTO, L.; SILVA, M.L.; LEITE, H.G.; GARCIA, R.; ARAUJO, G.A.A. A simulation model for evaluating technical and economic aspects of an industrial eucalyptus-based agroforestry system in Minas Gerais, Brazil. Agroforestry Systems, v.55, n.1, p.73-80, 2002.

FEDERAÇÃO DAAGRICULTURA E PECUÁRIA DO ESTADO DE MATO GROSSO - FAMATO. Diagnóstico de florestas plantadas do Estado de Mato Grosso. Cuiabá: IMEA, 2013. 106p.

Revista Árvore, Viçosa-MG, v.39, n.5, p.893-903, 2015 
ORGANIZACIÓN DE LAS NACIONES UNIDAS PARA LAALIMENTACIÓN Y LAAGRICULTURA

- FAO. Evaluación de los recursos forestales mundiales 2010: informe principal. Roma: 2010.381p. (Estudio FAO: Montes, 163).

GONÇALVES, J.L.M.; STAPE, J.L.; BENEDETTI, V.; FESSEL, V.A.G.; GAVA, J.L. Reflexos do cultivo mínimo e intensivo do solo em sua fertilidade e nutrição das árvores. In: GONÇALVES, J.L.M.; BENEDETTI, V. Nutrição e fertilização florestal. Piracicaba: IPEF, 2005. p.3-57.

GURGEL FILHO, O.A. Plantio de eucalipto consorciado com milho. Silvicultura em São Paulo, v.1, n.1, p.85-102, 1962.

IGLESIAS-TRABADO, G.; CARBALLEIRATENREIRO, R.; FOLGUEIRA-LOZANO, J. Eucalyptus universalis: global cultivated eucalyptus forests map version 1.2. Lugo: GIT Forestry Consulting. 2011. Disponível em: http:// git-forestry.com/

download_git_eucalyptus_map.htm. Acessado em: 27 ago. 2014

KEOGH, R.M. La teca y su importancia económica a nivel mundial. In: CAMINO, R. Las

plantaciones de teca en América Latina: mytos y realidades. Turrialba: CATIE, 2013. p.8-28. (Série Técnica. Informe Técnico/ CATIE, 397)

LEITE, H.G.; NOGUEIRA, G.S.; CAMPOS, J.C.C.; TAKIZAWA, F.T.; RODRIGUES, F.L. Um modelo de distribuição diamétrica para povoamentos de Tectona grandis submetidos a desbaste.

Revista Árvore, v.30, n.1, p.89-98, 2006.

LEITE, H.G.; OLIVEIRA, F.H.T. Statistical procedure to teste identity between analytical methods. Communications in Soil Science and Plant Analysis, v.33, n.7/8, p.1105-1118, 2002.

MACEDO, R.L.G.; VALE, A.B.; VENTURIN, N. Eucalipto em sistemas agroflorestais. Lavras: Universidade Federal de Lavras, 2010. 331p.

MACEDO, R.L.G.; BEZERRA. R.G.; VENTURIN, N.; VALE, R.S.; OLIVEIRA, T.K. Desempenho

Revista Árvore, Viçosa-MG, v.39, n.5, p.893-903, 2015 silvicultural de clones de eucalipto e características agronômicas de milho cultivados em sistema silviagrícola. Revista Árvore, v.30, n.5, p.701-709, 2006.

MORETTi, M.S. Crescimento de plantas clonais e seminais de Tectona grandis L.f. em monocultivo e sistema taungya com milho no município de Figueirópolis D'Oeste, estado de Mato Grosso. 2013. 109f. Dissertação (Mestrado em Ciências Florestais e Ambientais) - Universidade Federal de Mato Grosso, Cuiabá, 2013.

MORETTI, M.S.; TSUKAMOTO FILHO, A.R.; COSTA, R.B.; RONDON NETO, R.M.;

MEDEIROS, R.A.; SOUSA, R.A.T.M. Crescimento inicial de plantas de teca em monocultivo e sistema Taungya com milho em Figueiropolis D ' Oeste , Estado de Mato Grosso. Scientia Forestalis, v.42, n.102, p.269-277, 2014.

PASSOS, C.A.M.; FERNANDES, E.N.; COUTO, L. Plantio consorciado de Eucalyptus grandis com milho no Vale do Rio Doce, Minas Gerais. In: ENCONTRO BRASILEIRO DE ECONOMIA E PLANEJAMENTO FLORESTAL, 2., 1992. Curitiba. Anais... Colombo: Embrapa-CNPF, 1992. v.1.p.409-421.

PASSOS, C.A.M. Comportamento inicial do eucalipto (Eucalyptus grandis W. Hill ex Maiden) em plantio consorciado com feijão (Phaseolus vulgaris L.) no Vale do Rio Doce, Minas Gerais. 1990. 64f. Dissertação (Mestrado em Ciência Florestal) - Universidade Federal de Viçosa, Viçosa, MG, 1990.

REGAZZI, A.J.; SILVA, C.H. Testes para verificar a igualdade de parâmetros e a identidade de modelos de regressão não-linear em dados de experimento com delineamento em blocos casualizados. Ceres, v.57, n.3, p.315-320, 2010.

SALDANHA, F.B. Omissão de nutrientes em Tectona grandis no município de Anhembi (SP). In: ENCONTRO BRASILEIRO DE SILVICUlTURA, 3., 2014. Campinas. Anais... Curitiba: Embrapa, 2014. p.326-329.

SCHLÖNVOIGT, A.; BEER, J. Initial growth of pioneer timber tree species in a Taungya system 
in the humid lowlands of Costa Rica.

Agroforestry Systems, n.51, p.97-108, 2001.

SCHUUHLI, G.S.; PALUDZSZYN FILHO, E. O

cenário da silvicultura de teca e perspectivas para o melhoramento genético. Pesquisa Florestal Brasileira, v.30, n.63, p.217-230, 2010.

SMIT, L.; ARIAS, L.A.U.; SILVA, A.P.; OESTREICH FILHO, E. Plantation

performance of teak clones and seeds in different types of soils at 5,2 years of age in Tangará da Serra, Mato
Grosso, Brazil. San José, Costa Rica: CATIE/ FAO/TEAKNET, 2011. Palestra proferida na International Teak-Conference. Disponível em: http://web.catie.ac.cr/conferencia teca/ presentaciones/Sesion_7_7.pdf Acessado em: 19 nov. 2013.

TONINI, H.; SCHNEIDER, P.R.; FINGER, C.A.G. Curvas de índice de sítio para povoamentos clonais de Eucalyptus saligna Smith para a depressão central e serra do sudeste, Rio Grande do Sul. Ciência Florestal, v.16, n.1, p.27-43, 2006. 